\title{
Cardiomyogenic Heterogeneity of Clonal Subpopulations of Human Bone Marrow Mesenchymal Stem Cells
}

\author{
Tripathy $\mathrm{NK}^{\# 1}$, Rizvi $\mathrm{SHM}^{\# 1}$, Singh $\mathrm{SP}^{1}$, Garikpati VNS ${ }^{1}$, Nityanand $\mathrm{S}^{1}$
}

\begin{abstract}
We have evaluated the cardiomyogenic potential of clonal populations of human bone marrow mesenchymal stem cells (BM-MSC). Four rapidly proliferating clones of BM-MSC were obtained from the BM of a healthy donor which were then treated with 5-azacytidine and evaluated for the expression of GATA-4, NKx-2.5, FOG-2, TDGF-1, $\beta$-MHC, MEF2D and NPPA genes and cTnT, Desmin and $\beta$-MHC proteins. Of the four clones (i) Clone-1 had high expression of GATA-4 (1.89 fold ( $<<0.05)$, Nkx2.5 (2.29 fold; $\mathrm{p}<0.05)$, FOG2 (2.76 fold; $\mathrm{p}<0.05$ ), TDGF1 (6.97 fold, $\mathrm{p}<0.005)$, $\beta$ MHC (10.22 fold; $\mathrm{p}<0.005)$, MEF-2D (1.91 fold; $\mathrm{p}<0.005)$ and NPPA (1.65 fold; $\mathrm{p}<0.005)$; (ii) clone-2 had up-regulation of Nkx2.5 (1.98 fold; $\mathrm{p}<0.05$ ) but down-regulation of rest of the genes; (iii) clone-3 had up-regulation of Nkx2.5 (2.11 fold; $\mathrm{p}<0.05)$, TDGF1 (1.88 fold; $\mathrm{p}<0.05)$, MEF-2D (1.30 fold; $\mathrm{p}<0.05)$ and NPPA (1.21 fold; $\mathrm{p}<0.05)$, down regulation of GATA-4 and Fog-2 but no change in $\beta \mathrm{MHC}$ gene; and (iv) clone-4 had up-regulation of MEF-2D (1.17 fold; $\mathrm{p}<0.05)$ and down regulation of GATA-4, Nkx2.5 but no change in other genes compared to untreated cells of the clones. At the protein level, clone-1 expressed cTnT, Desmin, and $\beta$ MHC; clone-2 Desmin only while clones-3 and 4 each expressed cTnT, Desmin, and BMHC. Our data shows that BM-MSC are a heterogenous population of stem cells with sub-populations exhibiting a marked difference in the expression of cardiac markers both at gene and protein levels. This highlights that administering selected sub-populations of BM-MSC with a cardiomyogenic potential may be more efficacious than whole population of cells for cardiac regeneration.
\end{abstract}

Key Words: Human bone marrow mesenchymal stem cells, Clonal subpopulations, Cardiac heterogeneity

\section{Introduction}

Bone marrow-derived mesenchymal stem cells (BM-MSC) are being widely explored for cardiac regenerative therapy ${ }^{[1-3]}$, based on their ability to differentiate into cardiomyocytes in vitro and in the damaged myocardium in vivo ${ }^{[4-6]}$. In addition, their secretome is also reported to contribute to the therapeutic effects by paracrine mechanisms ${ }^{[7,8]}$. However, BM-MSC based cell therapy has not been able to reach an optimal clinical translation stage in cardiac regeneration because of variable therapeutic effects in different pre-clinical and clinical studies ${ }^{[9-11]}$. One of the factors could be variability in the MSC population used for therapy.

For several years BM-MSC have been considered to be a homogenous population of stem cells with a uniform multipotent differentiation potential. It is only recently that data is emerging on subpopulations of BM-MSC with varying biochemical, metabolic and functional characteristics ${ }^{[12-14]}$. Thus, our hypothesis was that there may be cardiac heterogeneity amongst sub-populations of MSC and infusing populations with optimal cardiomyogenic potential would have a bearing in cardiac regeneration.

Therefore, the aim of the present study was to evaluate cardiomyogenic heterogeneity of BM-MSC by analyzing expression of cardiomyogenic genes and cardiac structural proteins in 5-azacitidine treated single cell-derived clonal subpopulations of human BM-MSC.

\begin{abstract}
Materials and Methods
The BM-MSC were isolated, cultured and characterized as described earlier ${ }^{[11]}$. Briefly, after obtaining informed consent, approximately $10 \mathrm{ml}$ of bone marrow aspirate from iliac crest of a healthy volunteer was collected into heparinized tube. The mononuclear cells obtained from the aspirate by density gradient centrifugation were cultured in $25 \mathrm{~cm}^{2}$ flasks (BD Biosciences, USA) at $37^{0} \mathrm{C}$ in $5 \% \mathrm{CO}_{2}$ using $5 \mathrm{ml}$ of complete culture media consisting of $\alpha$-MEM, $1 \%$ glutamax, $16.5 \%$ fetal bovine serum, $100 \mathrm{U} / \mathrm{ml}$ penicillin and $100 \mathrm{~g} / \mathrm{ml}$ streptomycin (all from Gibco, Thermo Fisher Scientific, USA). After 48 hours, non-adherent cells were removed and medium was replaced. When culture reached $70-80 \%$ confluency, adherent cells were harvested using $0.05 \%$ trypsin (Gibco) and the cells were replated. Finally, $2^{\text {nd }}$ passage cells were subject to limiting dilution assay to generate single cell derived clones.
\end{abstract}

Osteogenic and Adipogenic Differentiation:

The BM-MSC were treated with osteogenic medium consisting of DMEM medium (Gibco) containing 10\% FBS (Hyclone, GE lifesciences, USA), $1 \mathrm{mM}$ dexamethasone, $10 \mathrm{mg} / \mathrm{mL}$ glyceraldehydes 3-phosphate, and $0.1 \mathrm{mM}$ ascorbic acid (osteogenesis kit, Chemicon, Merck's life science, Germany). 
After 21 days, the cells were fixed with $4 \%$ paraformaldehyde and stained with alizarin red stain to visualize mineralization. For adipogenic differentiation, BM-MSC were treated with adipogenic medium consisting of DMEM medium (Gibco) containing 10\% FBS (Hyclone), $500 \mathrm{mM}$ IBMX, $1 \mathrm{mM}$ dexamethasone, $10 \mathrm{mg} / \mathrm{mL}$ insulin, and $100 \mathrm{mM}$ indomethacin (adipogenesis kit, Chemicon). After 18 days, the cells were fixed and stained with oil red $\mathrm{O}$ stain to visualize the fat droplets in the cells.

\section{Flow-cytometry}

The phenotype of BM-MSC and their clones was analyzed by two color flow cytometry using flourescein isothiocyanate (FITC)) conjugated CD34, CD45 and HLA-DR and phycoerythrin (PE) conjugated CD73, CD90 and CD105 monoclonal antibodies (all from AbD Serotec, Bio-Rad, USA). The flow-cytometer used was FACScalibur (BD Biosciences) and data analysis was done using FACS express software.

\section{Limiting Dilution Assay}

Single cell-derived BM-MSC clones were generated by limiting dilution method ${ }^{[15]}$. Briefly, $2^{\text {nd }}$ passage BM-MSC were plated into four, 96 well tissue-culture plates at a density of 0.5 cells per well, each well contained $50 \mu \mathrm{l}$ fresh complete culture media and $50 \mu \mathrm{l}$ MSC conditioned media. To ensure single cell-derived clones of BMMSC, this method of limiting dilution was used as out of two consecutive wells only one well had a single cell while the other well had no cell. After 24 hours of culture under standard conditions each well was investigated under microscope and wells that contained single cell were marked. Every $2^{\text {nd }}$ day $50 \mu 1$ media was removed from each well and made up to $100 \mu \mathrm{l}$ with $50 \mu \mathrm{l}$ fresh complete culture media. After 8-10 days the sub-confluent cultures were harvested by trypsinization and transferred to six well tissue culture plates (BD Biosciences) and finally the cultures were maintained in $25 \mathrm{~cm}^{2}$ flasks for further experiments.

\section{Real Time Quantitative PCR:}

BM-MSC clones were treated with 5-azacytidine and total RNA of the cells was isolated with RNA AQUEOUS KIT (Ambion, Thermo Fisher Scientific, USA) and reverse-transcribed into cDNA with High Capacity cDNA Reverse Transcription kit (Applied Biosystems, Thermo Fisher Scientific, USA). Quantitative real-time PCR was performed using LightCycler 480 Roche, USA. Real time assays were done with HotStart-IT SYBR Green qPCR Master Mix (USb, Thermo Fisher Scientific, USA) according to manufacturer's protocol. PCR amplification were performed at $94^{\circ} \mathrm{C}$ for $1 \mathrm{~min}$ followed by 40 cycles of $94^{\circ} \mathrm{C}$ for 15 seconds, $56^{\circ} \mathrm{C}$ for 30 seconds $72^{\circ} \mathrm{C}$ for $1 \mathrm{~min}$. Melting curve was obtained by incubating the reactions at $94^{\circ} \mathrm{C}$ for $5 \mathrm{sec}, 65^{\circ} \mathrm{C}$ for $1 \mathrm{~min}$, and continuous at $94^{\circ} \mathrm{C}$. Each PCR was performed in triplicate to ensure the reproducibility of the results. Dissociation reactions were performed to confirm that all the primer sets were giving only single product. Results were expressed relative to the housekeeping gene glyceraldehyde 3 phosphate dehydrogenase (GAPDH). Oligonucleotides used as primers (From MWG Bangalore, India) in this study are given in Table 1 . The relative quantitative value of target gene, normalized to an endogenous control GAPDH (housekeeping) gene and relative to a calibrator (control), is expressed as $2-\Delta \Delta \mathrm{Ct}$ (-fold difference), where $\Delta \mathrm{Ct}=(\mathrm{Ct}$ of target genes $-\mathrm{Ct}$ of endogenous control gene (GAPDH), and $\Delta \Delta \mathrm{Ct}=(\Delta \mathrm{Ct}$ of samples for target gene $)-(\Delta \mathrm{Ct}$ of calibrator for the target gene).

Table-1: List of primers

\begin{tabular}{|c|c|c|}
\hline Name & Sequence & Accession number \\
\hline $\begin{array}{l}\text { GATA4 Forward } \\
\text { GATA4 Reverse }\end{array}$ & $\begin{array}{l}\text { GCT CCT TCA GGC AGT GAG AG } \\
\text { CTG TGC CCG TAG TGA GAT GA }\end{array}$ & NM_002052.3 \\
\hline $\begin{array}{l}\text { Nkx2.5 Forward } \\
\text { Nkx2.5 Reverse }\end{array}$ & $\begin{array}{l}\text { CTTCAAGCCAGAGGCCTACG } \\
\text { CCGCCTCTGTCTTCTTCAGC }\end{array}$ & $\underline{\text { NM } 004387.3}$ \\
\hline $\begin{array}{l}\text { FOG-2 Forward } \\
\text { FOG-2 Reverse }\end{array}$ & $\begin{array}{l}\text { GCTTCTATTTTGCCCACAGC } \\
\text { CTTCTCTTTGCCTCCCACTG }\end{array}$ & NM_012082.3 \\
\hline $\begin{array}{l}\text { TDGF1 Forward } \\
\text { TDGF1 Reverse }\end{array}$ & $\begin{array}{l}\text { GGATACCTGGCCTTCAGAG } \\
\text { CGCACATCGTGCTCACAGTT }\end{array}$ & NM 003212.2 \\
\hline $\begin{array}{l}\beta \text { MyHC Forward } \\
\beta \text { MyHC Reverse }\end{array}$ & $\begin{array}{c}\text { GAGC CTCC AGAG TTTG CTGA AGGA } \\
\text { TTGG CACG GACT GCGT CATC }\end{array}$ & $\begin{array}{l}\text { NM } 000257.2 \text { for MYH7 } \\
\text { NM } 002471.2 \text { for MYH6 }\end{array}$ \\
\hline $\begin{array}{l}\text { GAPDH Forward } \\
\text { GAPDH Reverse }\end{array}$ & $\begin{array}{l}\text { GA TTT GGT CGT ATT GGG } \\
\text { TCC ACG ACG TAC TCA GC }\end{array}$ & $\underline{\text { NM } 002046.3}$ \\
\hline
\end{tabular}




\section{Immunofluorescence}

The cells were grown on poly-L-lysine coated cover slips in 12 well tissue culture plates (BD Biosciences), and then treated with complete culture medium containing $10 \mu \mathrm{M}$ 5-azacytidine (Sigma-Aldrich, Merck's Life Science, Germany). Control cells were treated with complete medium alone. After incubating for $24 \mathrm{~h}$, the experimental and control cells were washed twice with PBS (Gibco) and further incubated in complete culture medium. The medium was changed every three days and the experiment was terminated at 21 days after 5 -azacytidine treatment. Cells were fixed in $4 \%$ paraformaldehyde (Sigma-Aldrich), permeabilized with $0.1 \%$ triton X (Sigma-Aldrich), non-specific binding sites were blocked with $5 \%$ sheep serum (Hyclone) and $0.1 \%$ triton $\mathrm{X}$ in PBS. Thereafter, primary antibodies against beta myosin heavy chain (bMHC) (1:100 dilution), cardiac troponin T (cTnT) (1:100 dilution) (all from Abcam, UK) and desmin (AbD Serotec) were added. Hoechst $2.5 \mathrm{mg} / \mu \mathrm{l}$ (Sigma-Aldrich) in PBS was added to stain nucleus. The cells were observed under fluorescent microscope (Nikon, Japan).

\section{Statistical analysis}

All experiments were performed for a minimum of three times and results have been presented as mean \pm SE. Statistical analysis was performed using SPSS 14.0 statistical package (SPSS Inc., USA).
Statistical significance of the results was determined using student tTest. Differences were considered statistically significant at $\left({ }^{*} \mathrm{p}<\right.$ $0.05)$.

\section{Results}

\section{$B M-M S C$}

The primary cultures of BM-MSC had fibroblastoid morphology, expressed CD73, CD90, and CD105 but had no expression of CD34, CD45 and HLA-DR. On treatment with lineage-specific induction medium they differentiated into adipogenic and osteogenic lineages, as evidenced by Oil red-O and Alizarin red staining, respectively (Figure 1).

\section{BM-MSC Clones}

The limiting dilution of primary culture BM-MSC yielded a total of nine clones out of which only four clones exhibited rapid growth and survived till sixth passage in culture. All these rapidly growing clones had comparable expression of mesenchymal markers CD73, CD90, CD105 but no expression of CC34, CD45 and CD105 (Figure 2A). These clones were subsequently analyzed for evaluation of their cardiomyogenic potency.

A

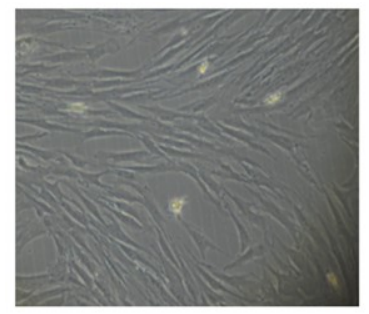

B
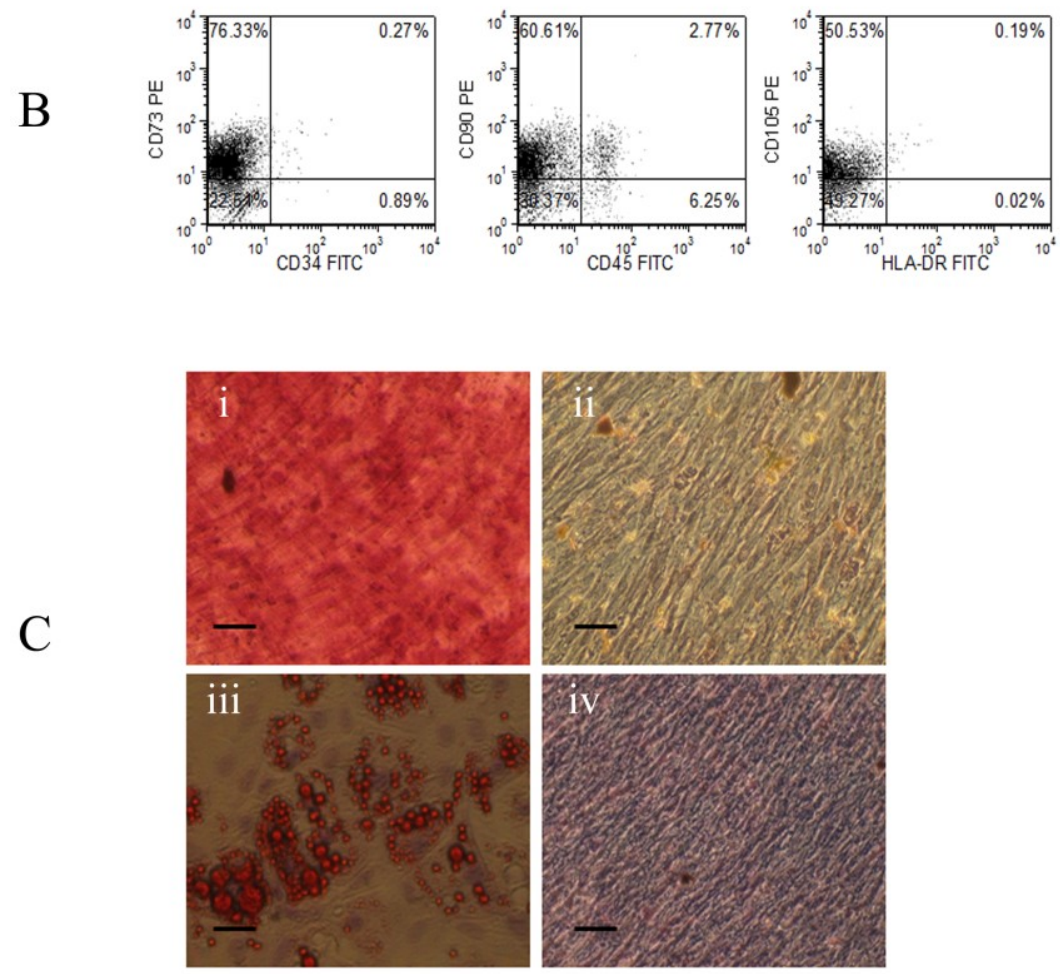

Figure 1:

(A) Photomicrograph of BM-MSC showing fibroblastoid morphology (10X).

(B) Flow cytometric dot plots showing CD73, CD90, CD105 positive and CD34, CD45 and HLA-DR negative phenotype of BM-MSC

(C) Alizarin Red staining of BM-MSC showing osteogenic differentiation of (i) induction medium treated and (ii) control cells. Oil-Red-O staining of BM-MSC showing adipogenic differentiation of (iii) induction medium treated cells; (iv) control cells (10X). 

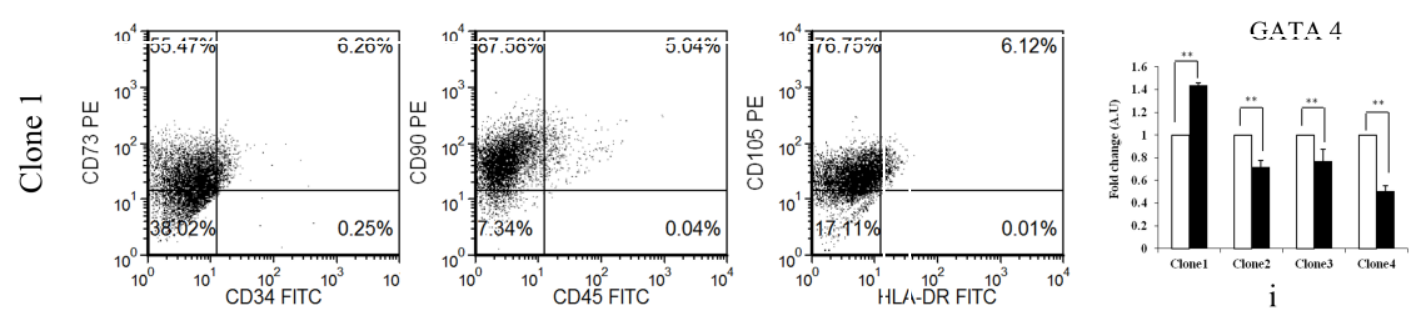

Nk: 2.5
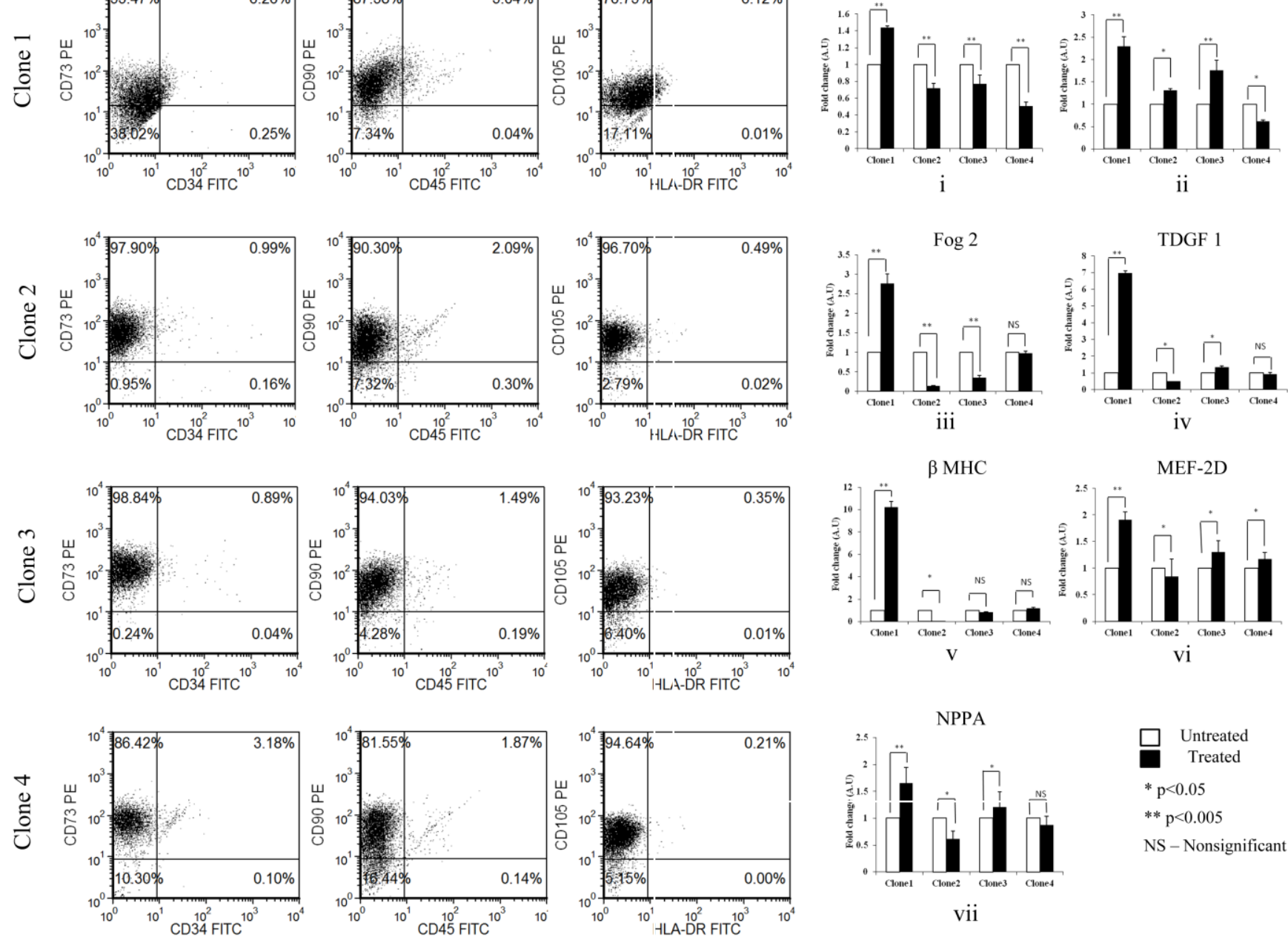

A

B

Clone 1

Clone 2

Clone 3

Clone 4
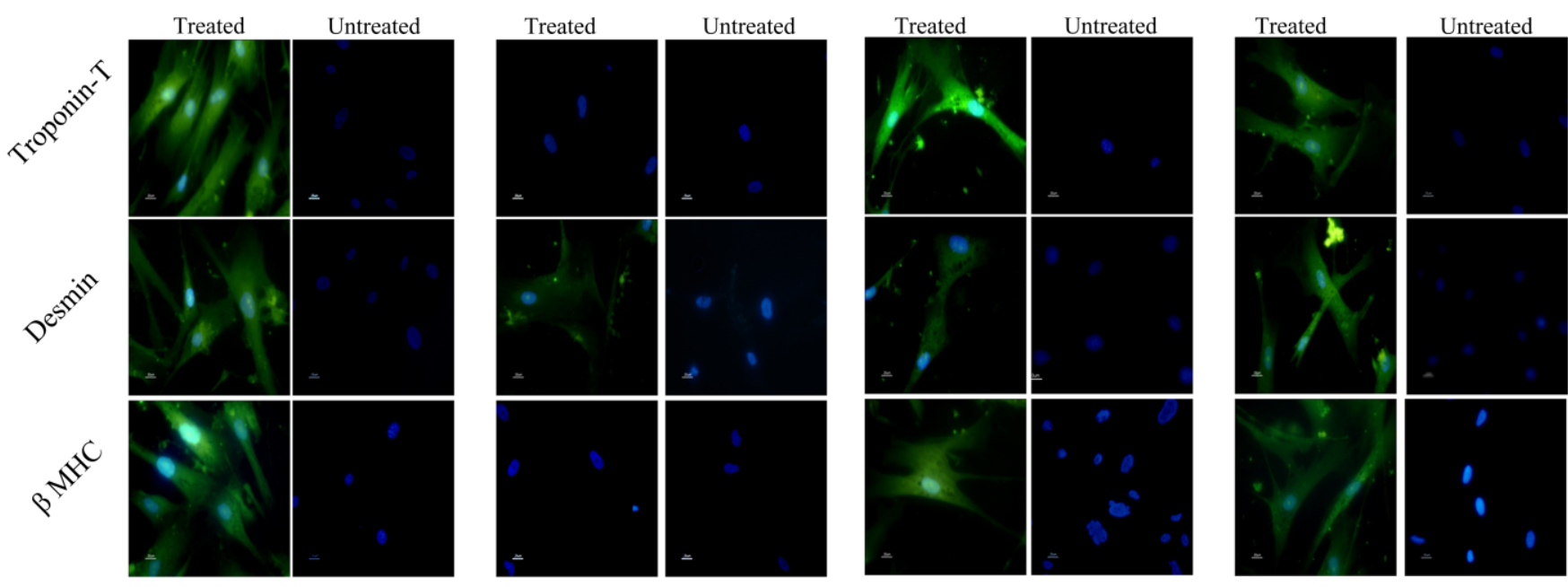

$\mathrm{C}$

Figure 2:

(A) Flow cytometric dot plots showing that BM-MSC clones have a CD73, CD90,CD105 positive and CD34, CD45 and HLA-DR negative phenotype.

(B) Expression of cardiomyogenic genes; (i) GATA4, (ii) NKx2.5, (iii) FOG2, (iv) TDGF1, (v) BMHC, (vi) MEF-2D and (vii) NPPA by 5-azacytidine treated human BM-MSC clones. All values were normalized to glyceraldehyde-3-phosphate dehydrogenase (GAPDH) and expressed as mean $\pm S E$ of three independent experiments. ${ }^{*} p<0.05$ and ${ }^{* *} p<0.005$.

(C) Immunofluorescence staining of cardiac specific proteins viz. Cardiac Tropnin-T (cTnT, desmin, and beta-myosin heavy chain ( $\beta$-MHC), in 5-azacytidine treated human BM-MSC clones viewed under phase contrast microscope (40X). 
Cardiomyogenic genes in BM-MSC clones

The expression of cardiomyogenic genes in the four rapidly growing BM-MSC clones obtained was as follows. The clone-1 had significantly increased expression of GATA4 (1.89 fold $(\mathrm{p}<0.05)$, Nkx2.5 (2.29fold; $\mathrm{p}<0.05), \quad$ FOG2 (2.76fold; $\mathrm{p}<0.05)$, TDGF1 (6.97fold, $\mathrm{p}<0.005), \beta \mathrm{MHC}(10.22$ fold; $\mathrm{p}<0.005)$, MEF-2D (1.91 fold; $\mathrm{p}<0.005)$ and NPPA (1.65 fold; $\mathrm{p}<0.005)$ as compared to its untreated cells taken as control. The clone- 2 had increased expression only of Nkx2.5 (1.98 fold; $\mathrm{p}<0.05$ ) but down-regulation of GATA4, FOG2, TDGF1, $\beta$ MHC, MEF-2D and NPPA genes as compared to its control. Clone-3 had increased expression of $\mathrm{Nkx} 2.5$ (2.11 fold; $\mathrm{p}<0.05)$, TDGF (1.88 fold; $\mathrm{p}<0.05)$, MEF-2D (1.30 fold; $\mathrm{p}<0.05)$ and NPPA (1.21 fold; $\mathrm{p}<0.05)$, down regulation of GATA4 and Fog2 but no difference in the expression of $\beta-\mathrm{MHC}$ as compared to its control. The clone-4 had up-regulation of MEF-2D (1.17 fold; $p<0.05)$ and down-regulated expression of GATA4 and Nkx2.5 but no difference in the expression levels of TDGF1, FOG2, $\beta$ MHC and NPPA genes as compared to its control (Figure 2B).

\section{Cardiomyogenic proteins in BM-MSC clones}

The expression of cardiac structural proteins in the four rapidly growing BM-MSC clones obtained was as follows. The Clone-1 stained positive for all the three cardiac structural proteins namely cTnT, Desmin and $\beta$ MHC. The clone-2 was positive for Desmin but lacked expression of cTnT and $\beta \mathrm{MHC}$ proteins. Clone-3 and clone-4, each was positive for $\mathrm{cTnT}$, Desmin and $\beta \mathrm{MHC}$ proteins. The untreated cells of these clones which were taken as control had no staining for any of these proteins (Figure 2C).

\section{Discussion}

The present study reports that human BM-MSC consist of different subpopulations of stem cells having variable degree of cardiomyogenic potency as revealed by expression of GATA-4, Nkx2.5, FOG2, TDGF1 and BMHC cardiomyogenic genes and cTnT, Desmin and $\beta \mathrm{MHC}$ cardiac structural proteins in 5-azacytidine pretreated single cell derived BM-MSC clones. The study also shows that only a small fraction of whole population of BM-MSC possesses optimal cardiomyogenic potency at gene and protein levels.

We have established single cell-derived clonal subpopulations of BM-MSC from the bone marrow aspirate of a single donor to evaluate cardiomyogenic potency of individual clones of whole population of BM-MSC. All these clones expressed comparable level of mesenchymal specific markers showing a homogenous population of cells. However, following cardiomyogenic induction with 5azacytidine, we observed a highly variable pattern of cardiac gene expression in these clones. The clone-1 had up-regulation of all the five cardiac genes studied namely GATA-4, Nkx2.5, FOG2, TDGF1 and $\beta \mathrm{MHC}$; clone-2 had up-regulation of only Nkx2.5 but downregulation of rest of the genes; clone-3 had up-regulation of $\mathrm{Nkx} 2.5$ and TDGF1 while down regulation of GATA4 and Fog2 but no change in $\beta$-MHC; and clone-4 had down-regulation of GATA4 and $\mathrm{Nkx} 2.5$ but no change in rest of the cardiac genes. This heterogeneity of cardiac gene expression in our BM-MSC clones is consistent with the data of a recent study reporting differential expression of osteogenic genes osteocalcin, RUNX2, and osterix in different clonal subpopulations of equine BM-MSC ${ }^{[16]}$. The differentiation of stem cells into functional cardiomyocytes requires a combinatorial action of multiple transcription factors including GATA-4, Nkx2.5, FOG2, TDGF- 1 and $\beta$-MHC ${ }^{[17,18]}$. Of these GATA-4 functions as a master transcription factor and a critical regulator for induction of other cardiac genes in stem cells and their differentiation into cardiomyocytes ${ }^{[19,20]}$. Moreover, the GATA-4 deficient stem cells are reported not to differentiate into cardiomyocytes ${ }^{[21]}$.
Thus, in the light of these studies, it is likely that clone-1 expressing GATA-4 and other cardiac genes may be fully programmed towards cardiomyogenic lineage. The remaining clones which had downregulation of GATA-4 had either down-regulation or no upregulation of most of the cardiac genes studied and thus may have partial or no programming towards cardiac lineage.

We also evaluated expression of cardiac structural proteins cTnT, Desmin and $\beta \mathrm{MHC}$ in the 5-azactidine treated BM-MSC clones. Clone-1 similar to its gene profile expressed all the three cardiac proteins cTnT, Desmin and $\beta$ MHC. Clone-2 was positive only for Desmin which was also matching with its gene expression profile showing up-regulation of only one gene. However, it was surprising to note that clone- 3 which exhibited up-regulation of $\mathrm{Nkx} 2.5$ and TDGF1 genes only and clone-4 with up-regulation of none of the cardiac genes studied, also stained positive for cTnT, Desmin and $\beta \mathrm{MHC}$ proteins. Although the reason for expression of cardiac structural proteins in these clones having poor cardiomyogenic genetic programming, is not clear but since both of these subpopulations had no up-regulation of GATA-4, which is essential for terminal differentiation and survival of stem cells ${ }^{[20,21]}$, these cells may represent partially differentiated or progenitor cardiac cells undergoing apoptosis.

In addition, we analyzed gene expression of NPPA and MEF2D representing functional and structural markers of mature cardiomyocytes, respectively. It was observed that similar to other cardiac genes, the cardiomyocytic cells differentiated from clone -1 had a high expression of NPPA and MEF2D indicating their functional and structural maturity.

From our data it emerges that only a small fraction of BM-MSC express complete repertoire of cardiac genes and proteins. This corroborates with a recent study which showed that on 5-azacytidine induction only eight of twenty-four MSC clones expressed cardiac specific markers and exhibited electrophysiological properties typical of functional cardiomyocytes, while the rest of the clones with low cardiac markers did not display electrophysiological features, and thus less than $30 \%$ of MSC contributed to functional cardiomyocytic differentiation ${ }^{[22]}$. Similarly, a single clonal population of human BM-MSC which expressed high levels of cardiac markers on cardiomyogenic induction was shown to have a greater beneficial effect in cardiac repair in rats than whole population of BM-MSC and thus indicating further that only a small fraction of BM-MSC has cardiomyogenic potential ${ }^{[23]}$. This cardiomyogenic heterogeneity in BM-MSC may be responsible for the non-congruent results of preclinical studies and clinical trials reported in the literature over the past decade ${ }^{[24]}$.

We investigated BM-MSC obtained from a single donor, since donor to donor variation is a major contributor to differences in the biologic properties of $\mathrm{BM}-\mathrm{MSC}^{[25]}$ and we wanted to avoid any donor specific variation in the cardiomyogenic potency of these stem cells. However, this data needs to be further confirmed by using a cohort of subjects and evaluating the efficacy of different clonal subpopulations in a suitable experimental model of myocardial infarction.

\section{Conclusion}

In summary, our data shows that human BM-MSC exhibit cardiomyogenic heterogeneity and only a small fraction of these stem cells express the complete panel of the studied cardiac markers both at the gene and protein level. This highlights that for cardiac regeneration, therapy with sub-populations of BM-MSC with a cardiomyogenic potential may be more optimal than whole population of BM-MSC. 


\section{References}

1. Williams AR, Hare JM. Mesenchymal stem cells: biology, pathophysiology, translational findings, and therapeutic implications for cardiac disease. Circ Res. 2011;109(8):923-40.

2. Chou SH, Lin SZ, Kuo WW, Pai P, Lin JY, Lai CH, Kuo CH, Lin $\mathrm{KH}$, Tsai FJ, Huang CY. Mesenchymal stem cell insights: prospects in cardiovascular therapy. Cell Transplant. 2014;23(45):513-29.

3. Karantalis V, Hare JM. Use of mesenchymal stem cells for therapy of cardiac disease. Circ Res. 2015;116(8):1413-30.

4. Toma C, Pittenger MF, Cahill KS, Byrne BJ, Kessler PD. Human mesenchymal stem cells differentiate to a cardiomyocyte phenotype in the adult murine heart. Circulation. 2002;105(1):93-8.

5. Piryaei A, Soleimani M, Heidari MH, Saheli M, Rohani R, Almasieh M. Ultrastructural maturation of human bone marrow mesenchymal stem cells-derived cardiomyocytes under alternative induction of 5-azacytidine. Cell Biol Int. 2015;39(5):519-30.

6. Quevedo HC, Hatzistergos KE, Oskouei BN, Feigenbaum GS, Rodriguez JE, Valdes D, Pattany PM, Zambrano JP, Hu Q, McNiece I, Heldman AW, Hare JM. Allogeneic mesenchymal stem cells restore cardiac function in chronic ischemic cardiomyopathy via trilineage differentiating capacity. Proc Natl Acad Sci U S A. 2009;106(33):14022-7.

7. Duran JM, Makarewich CA, Sharp TE, Starosta T, Zhu F, Hoffman NE, Chiba Y, Madesh M, Berretta RM, Kubo H, Houser SR. Bonederived stem cells repair the heart after myocardial infarction through transdifferentiation and paracrine signaling mechanisms. Circ Res. 2013;113(5):539-52.

8. Gallina C, Turinetto V, Giachino C. A New Paradigm in Cardiac Regeneration:The Mesenchymal Stem Cell Secretome. Stem Cells Int. 2015;2015:765846.

9. Mazo M, Araña M, Pelacho B, Prosper F. Mesenchymal stem cells and cardiovascular disease: a bench to bedside roadmap. Stem Cells Int. 2012;2012:175979.

10. Telukuntla KS, Suncion VY, Schulman IH, Hare JM. The advancing field of cell-based therapy: insights and lessons from clinical trials. J Am Heart Assoc. 2013;2(5):e000338.

11. Singh SP, Tripathy NK, Nityanand S. Comparison of phenotypic markers and neural differentiation potential of multipotent adult progenitor cells and mesenchymal stem cells. World J Stem Cells. 2013;5(2):53-60.

12. Phinney DG. Functional heterogeneity of mesenchymal stem cells: implications for cell therapy. J Cell Biochem. 2012;113(9):280612.
Abbreviations
$\beta \mathrm{MHC}$ :
cTnT:
FOG-2:
GATA-4:
HLA:
IBMX:
MEF-2D:
NKX2-5:
NPPA:
RUNX2:
TDGF1:
Beta Myosin Heavy Chain
Cardiac Troponin T
Family of GATA member 2
GATA binding protein 4
Human Leukocyte Antigen
3-Isobutyl-1-methylxanthine
Myocyte-specific Enhancer Factor 2D
NK2 transcription factor related, locus 5
Natriuretic Peptide A
Runt-related transcription factor 2
Teratocarcinoma-Derived Growth Factor 1

13. Phinney DG. Biochemical heterogeneity of mesenchymal stem cell populations: clues to their therapeutic efficacy. Cell Cycle. 2007;6(23):2884-9.

14. Liu Y, Muñoz N, Bunnell BA, Logan TM, Ma T. DensityDependent Metabolic Heterogeneity in Human Mesenchymal Stem Cells. Stem Cells. 2015 ;33(11):3368-81.

15. Fedr R, Pernicová Z, Slabáková E, Straková N, Bouchal J, Grepl M, Kozubík A, Souček K. Automatic cell cloning assay for determining the clonogenic capacity of cancer and cancer stemlike cells. Cytometry A. 2013;83(5):472-82.

16. Radtke CL, Nino-Fong R, Rodriguez-Lecompte JC, Esparza Gonzalez BP, Stryhn H, McDuffee LA. Osteogenic potential of sorted equine mesenchymal stem cell subpopulations. Can J Vet Res. 2015;79(2):101-8.

17. Wu WS, Lai FJ. Detecting Cooperativity between Transcription Factors Based on Functional Coherence and Similarity of Their Target Gene Sets. PLoS One. 2016;11(9):e0162931.

18. Nemer G, Nemer M. Regulation of heart development and function through combinatorial interactions of transcription factors. Ann Med. 2001;33(9):604-10.

19. Charron F, Paradis P, Bronchain O, Nemer G, Nemer M. Cooperative interaction between GATA- 4 and GATA- 6 regulates myocardial gene expression. Mol Cell Biol.1999;19(6):4355-65.

20. Grépin C, Nemer G, Nemer M. Enhanced cardiogenesis in embryonic stem cells overexpressing the GATA-4 transcription factor. Development. 1997;124(12):2387-95.

21. Grépin C, Robitaille L, Antakly T, Nemer M. Inhibition of transcription factor GATA-4 expression blocks in vitro cardiac muscle differentiation. Mol Cell Biol. 1995;15(8):4095-102.

22. Wei F, Wang T, Liu J, Du Y, Ma A. The subpopulation of mesenchymal stem cells that differentiate toward cardiomyocytes is cardiac progenitor cells. Exp Cell Res. 2011;317(18):2661-70.

23. Zhang S, Ge J, Sun A, Xu D, Qian J, Lin J, Zhao Y, Hu H, Li Y, Wang K, Zou Y. Comparison of various kinds of bone marrow stem cells for the repair of infarcted myocardium: single clonally purified non-hematopoietic mesenchymal stem cells serve as a superior source. J Cell Biochem. 2006;99(4):1132-47.

24. Singh A, Singh A, Sen D. Mesenchymal stem cells in cardiac regeneration: a detailed progress report of the last 6 years (20102015). Stem Cell Res Ther. 2016;7(1):82.

25. Katsara O, Mahaira LG, Iliopoulou EG, Moustaki A, Antsaklis A, Loutradis D, Stefanidis K, Baxevanis CN, Papamichail M, Perez SA. Effects of donor age, gender, and in vitro cellular aging on the phenotypic, functional, and molecular characteristics of mouse bone marrow-derived mesenchymal stem cells. Stem Cells Dev. 2011;20(9):1549-61. 


\section{Potential Conflicts of Interests}

None

\section{Acknowledgements}

This work was supported by an extramural grant entitled "Mesenchymal Stem Cell Therapy in Myocardial Infarction, Stroke, Renal Failure and Diabetes" (BT/PR6519/MED/14/826/2005) sanctioned by Department of Biotechnology, Government of India, to Dr S Nityanand.

\section{Corresponding Author}

Soniya Nityanand, Prof \& Head, Dept. of Hematology, Sanjay Gandhi Post Graduate Institute of Medical Sciences, Raebareli Road.Lucknow -226014, UP, India. E-mail: soniya_nityanand@yahoo.co.in 